\title{
Al-MCM-41 Synthesized from Kaolin via Hydrothermal Route: Structural Characterization and Use as an Efficient Adsorbent of Methylene Blue
}

\author{
Evânia C. Santos, ${ }^{a}$ Luelc S. Costa, ${ }^{b}$ Edipo S. Oliveira, ${ }^{a}$ Raquel A. Bessa, ${ }^{a}$ \\ Armando D. L. Freitas, ${ }^{a}$ Cristiane P. Oliveira, ${ }^{a}$ Ronaldo F. Nascimento ${ }^{c}$ and \\ Adonay R. Loiola $*$,a \\ ${ }^{a}$ Departamento de Química Orgânica e Inorgânica, Universidade Federal do Ceará, \\ Campus do Pici, 60440-900 Fortaleza-CE, Brazil \\ ${ }^{b}$ Instituto de Química, Universidade Estadual de Campinas, 13083-872 Campinas-SP, Brazil \\ 'Departamento de Química Analítica e Físico-Química, Universidade Federal do Ceará, \\ Campus do Pici, 60440-900 Fortaleza-CE, Brazil
}

\begin{abstract}
The mesoporous material Al-Mobil Composition of Matter No. 41 (Al-MCM-41) was successfully obtained from kaolin, a low cost raw material, by means of hydrothermal route. The process of synthesis of Al-MCM-41 was based on calcination of kaolin, dealumination by acid treatment, hydrothermal synthesis in alkaline medium and surfactant extraction. The characterization of the obtained mesoporous material was carried out by techniques such as: X-ray diffraction, infrared vibrational spectroscopy, ${ }^{29} \mathrm{Si}$ and ${ }^{27} \mathrm{Al}$ solid state nuclear magnetic resonance, scanning electron microscopy, transmission electron microscopy and $\mathrm{N}_{2}$ adsorption-desorption. The $\mathrm{X}$-ray diffraction at low angles allowed the determination of the cell parameter, which was $4.02 \mathrm{~nm}$. The analyses of scanning and transmission electron microscopy revealed important morphological properties of the synthesized material. $\mathrm{N}_{2}$ adsorption/desorption showed a Brunauer-Emmett-Teller (BET) specific surface area of $1,303 \mathrm{~m}^{2} \mathrm{~g}^{-1}$, pore volume of $1.23 \mathrm{~cm}^{3} \mathrm{~g}^{-1}$ and average diameter of $2.45 \mathrm{~nm}$. The mesoporous material presented a maximum adsorption capacity of $316 \mathrm{mg} \mathrm{g}^{-1}$ for the cationic dye methylene blue (MB) in a concentration typical of industrial effluents, which makes it a potential adsorbent for MB removal from wastewaters.
\end{abstract}

Keywords: Al-MCM-41, kaolin, mesopores, methylene blue, adsorption

\section{Introduction}

There are many different types of commercially available dyes, and they usually have high stability to light, temperature, detergents and microbial attack. Approximately $3,500 \mathrm{t}$ of dye components are discharged into aqueous streams every year. ${ }^{1}$ In general, even very small amounts of dye in water (10-50 $\mathrm{mg} \mathrm{L}^{-1}$ ) are highly visible, affecting water transparency and disturbing the aquatic environment. ${ }^{2}$ Many dyes and their degradation products are toxic and carcinogenic, which requires efficient methods of removal from wastewaters. ${ }^{3}$ The azo dye is produced by diazotization of aromatic amines and is the most widely used class of dyes in industries such as textile, printing, leather, papermaking, etc. ${ }^{4}$ One important type of azo dye is methylene blue (MB), or 3,7-bis(dimethylamino)-phenothiazin-5-ium chloride, a

*e-mail: adonay@ufc.br cationic dye commonly applied to cotton, wood, and silk and that can cause various symptoms including difficulty in breathing, nausea, and vomiting, and can also impair photosynthetic processes in aquatic ecosystems. ${ }^{5}$ This way, there is a high demand for treatment of effluents containing such dye. ${ }^{6}$

Several chemical, physical and biological methods have been applied in order to remove dyes from wastewaters, including chemical coagulation/flocculation, ozonation, oxidation processes, ion exchange and ultrafiltration, but they can present considerable disadvantages as high cost and generation of secondary pollutants. ${ }^{7}$ Adsorption is an important method to remove dyes and to control the biochemical oxygen demand. ${ }^{8} \mathrm{~A}$ representative material used as adsorbent is activated carbon, which is widely used as adsorbent for removal of dyes, but it is found to be ineffective 
due to its high cost and low reusability. ${ }^{9}$ Due to properties such as high surface area, large pore size and pore volume, the mesoporous material Mobil Composition of Matter No. 41 (MCM-41) is especially attractive as adsorbent for organic dyes from wastewater. ${ }^{3,10}$ The traditional synthesis of this type of ordered mesoporous materials is based on the hydrothermal route that uses an organic source of silica, e.g., tetraethyl orthosilicate (TEOS) and a surfactant, which plays the role of the structure directing agent, and that must be removed after the silica condensation so that the mesopores become available. ${ }^{11-14}$ Such reagents are usually expensive and the MCM-41 materials built with pure-silica are of limited use for some applications, because of the lack of acid sites and poor ion-exchange capacity. ${ }^{15}$ Several studies have been devoted to the search of cheaper raw materials that could overcome the high costs associated with the synthesis of MCM-41. ${ }^{16-19}$ Different types of low cost materials as coal fly ash and clays have been used as alternative sources of silica and alumina in mesoporous materials synthesis, ${ }^{20,21}$ which was proven to be a way to decrease the costs involved in the synthesis processes.

One property that represents a limitation for the widespread industrial application of materials as MCM-41 is its relatively low thermal stability. ${ }^{22}$ Mesoporous materials in which silica is partially substituted by metallic species tend to present improved properties. For example, the incorporation of aluminum in MCM structure is important due to the nature of the acid sites, noticeably the Brönsted acid sites generated by the presence of tetrahedrallycoordinated aluminum. ${ }^{23}$ This way, the inclusion of metal cations into the silicate framework contributes to improve the acidic properties as well as the adsorptive properties. ${ }^{24-26}$ The Al-MCM-41, i.e., the MCM-41 containing framework aluminum, presents improved acidic characteristics and is considered to be of great importance for several applications..$^{27,28}$

In this work, we report the synthesis and the full characterization of the mesoporous material Al-MCM-41 by using calcined/dealuminated kaolin as the only silica and alumina source together with the surfactant cetyltrimethylammonium bromide (CTAB) in alkaline medium, and its use for removal of MB in aqueous medium.

\section{Experimental}

\section{Synthesis}

Prior to the mesoporous material synthesis, kaolin provided by Caulisa S. A. was calcined at $600{ }^{\circ} \mathrm{C}$ for $2 \mathrm{~h}$, with heating rate of $10{ }^{\circ} \mathrm{C} \mathrm{min}-1$. This step was necessary so that kaolin could be converted to its more reactive form, metakaolin. Then, metakaolin underwent a process of dealuminization by acid treatment. A sample of $10 \mathrm{~g}$ of metakaolin was transferred to a round flask of $500 \mathrm{~mL}$ capacity, in which $100 \mathrm{~mL}$ of $2.5 \mathrm{~mol} \mathrm{~L}^{-1} \mathrm{H}_{2} \mathrm{SO}_{4}$ were added. This mixture was heated at $90{ }^{\circ} \mathrm{C}$ for $2 \mathrm{~h}$ under reflux. The solid was centrifuged, washed with diluted sulfuric acid and deionized water and then dried overnight at $100{ }^{\circ} \mathrm{C}$.

The synthesis of the Al-MCM-41 material was based on the work of Okada et al. ${ }^{29}$ with modifications, and with a reaction mixture of 1.00:0.08:0.25:138 molar ratio of dealuminated-metakaolin:CTAB: $\mathrm{NaOH}_{2} \mathrm{H}_{2} \mathrm{O}$. First, $1.00 \mathrm{~g}$ of dealuminated metakaolin was mixed with $0.4756 \mathrm{~g}$ of CTAB together with $40 \mathrm{~mL}$ of $0.1 \mathrm{~mol} \mathrm{~L}^{-1} \mathrm{NaOH}$. The reaction mixture was submitted to magnetic stirring for $24 \mathrm{~h}$, followed by more $24 \mathrm{~h}$ of resting. This mixture was transferred to a Teflon-lined stainless-steel autoclave and crystallized by thermal treatment under autogenous pressure and static conditions at $110{ }^{\circ} \mathrm{C}$ for $24 \mathrm{~h}$. The as-synthesized material (CTAB-Al-MCM-41) was washed five times with distilled water and dried at $110^{\circ} \mathrm{C}$ overnight. In order to extract the surfactant, the sample was calcined at $600{ }^{\circ} \mathrm{C}$ for $4 \mathrm{~h}$, with heating rate of $1{ }^{\circ} \mathrm{C} \mathrm{min}-1$. A reference sample of MCM-41, without aluminum, was prepared following the method reported by Abu-Zied et al. ${ }^{14}$ For this, $2.5 \mathrm{~g}$ of CTAB were dissolved in $50 \mathrm{~g}$ of deionized water, in a polypropylene flask. Then, $17 \mathrm{~mL}$ of $28 \% \mathrm{~m} / \mathrm{m} \mathrm{NH}_{3}$ and $76 \mathrm{~mL}$ of ethanol were added to the surfactant solution. The mixture was stirred for $15 \mathrm{~min}$ and then $5 \mathrm{~mL}$ of TEOS were added, resulting in the formation of a gel. This gel was stirred for $2 \mathrm{~h}$ and aged for another $2 \mathrm{~h}$. The solid produced was centrifuged, washed with distilled water 6 times and dried overnight at $110{ }^{\circ} \mathrm{C}$. The sample was calcined at $600{ }^{\circ} \mathrm{C}$ for $4 \mathrm{~h}$, with heating rate of $1^{\circ} \mathrm{C} \mathrm{min}^{-1}$.

\section{Characterization}

$\mathrm{X}$-ray diffraction (XRD) analysis was performed in a Shimadzu XDR 7000 by using a Bragg-Brentano geometry. The powder pattern was collected in the continuous mode with scan speed of $2 \mathrm{~min}^{-1}(2 \theta) . \mathrm{Cu} \mathrm{K \alpha}(\lambda=0.154056 \mathrm{~nm})$ radiation was used with the tube operating at $40 \mathrm{kV}$ and $30 \mathrm{~mA}$.

The chemical compositions of the samples were determined by X-ray fluorescence (XRF) with a Rigaku spectrometer, model ZSX Mini II, operating with a tube of $\mathrm{Pd}(40 \mathrm{kV}, 1.2 \mathrm{~mA})$.

Fourier transform infrared (FTIR) measurements were performed with a PerkinElmer FT-IR Spectrum spectrometer, with a nominal resolution of $2 \mathrm{~cm}^{-1}$. Samples of the precursor materials, the as-synthesized and final Al-MCM-41 were prepared as wafers with $\mathrm{KBr}$ (3\% mass). 
CTAB, as-synthesized Al-MCM-41 and Al-MCM-41 samples were submitted for thermogravimetric (TG) analysis using a TA instruments Qseries-50 with a heating rate of $1{ }^{\circ} \mathrm{C} \mathrm{min}^{-1}$, in synthetic air with a flow rate of $50 \mathrm{~mL} \mathrm{~min}{ }^{-1}$. The temperature ranged from 30 to $800{ }^{\circ} \mathrm{C}$.

Nitrogen gas adsorption-desorption isotherms were obtained at $-196{ }^{\circ} \mathrm{C}$ over a wide relative pressure range from 0.01 to $0.995 \mathrm{~atm}$ with a volumetric adsorption analyser Micromeritics ASAP 2010. The sample was outgassed at $300^{\circ} \mathrm{C}$ for $24 \mathrm{~h}$ prior to the measurements. The specific area was calculated by Brunauer-Emmett-Teller (BET) method, considering the linear portion of the BET plot $\left(\mathrm{p} / \mathrm{p}_{\mathrm{o}}=0.05-0.25\right)$. The pore size distribution was calculated by the Barrett-Joyner-Halenda (BJH) method using the desorption isotherm.

${ }^{29} \mathrm{Si}$ and ${ }^{27} \mathrm{Al}$ solid state nuclear magnetic resonance (NMR) measurements of kaolin, metakaolin, as-synthesized Al-MCM-41 and Al-MCM-41 were carried out at 300 and $60 \mathrm{MHz}$ in a Bruker spectrometer, model Avance II.

Scanning electron microscopy (SEM) analyses were carried out in an FEI Quanta 450 FEG. The samples were prepared on double-sided carbon tape on an aluminum support and coated with a thin layer of gold.

Transmission electron microscopy (TEM) analyses were performed by using a few milligrams of the powder dispersed in isopropyl alcohol and sonicated for $15 \mathrm{~min}$. Two drops of the dispersion were placed onto a copper grid (300 mesh) with a lacey carbon film. The samples were analyzed in a $200 \mathrm{keV}$ JEOL-JEM 2100 microscope (spot size: $20-200 \mathrm{~nm}$ ).

\section{MB removal}

Al-MCM-41 was evaluated for the adsorption of MB by performing batches containing $50 \mathrm{mg}$ of Al-MCM- 41 in contact with $20 \mathrm{~mL}$ of $10 \mathrm{mg} \mathrm{L}^{-1} \mathrm{MB}$ solution under orbital stirring $(250 \mathrm{rpm})$, at $25^{\circ} \mathrm{C}$. The concentration of MB was determined by means of the maximum absorbance at $664 \mathrm{~nm}$, using a Shimadzu UV-1800 UV-Vis spectrophotometer. For kinetic measurements, solutions were collected at different intervals in a range of 1-360 min. For obtaining the adsorption isotherm, the experiments were carried out for $30 \mathrm{~min}$ so that the adsorption equilibrium could be reached. The data from the adsorption isotherm were used to determine the adsorption capacity, $\mathrm{q}_{\mathrm{e}}\left(\mathrm{mg} \mathrm{g}^{-1}\right)$, indicating the amount of adsorbed dye per amount of the dry adsorbent:

$\mathrm{q}_{\mathrm{e}}=\frac{\mathrm{v}\left(\mathrm{C}_{\mathrm{o}}-\mathrm{C}_{\mathrm{e}}\right)}{\mathrm{m}}$

where $\mathrm{v}$ is the solution volume $(\mathrm{L}), \mathrm{C}_{\mathrm{o}}$ the initial concentration $\left(\mathrm{mg} \mathrm{L}^{-1}\right), \mathrm{C}_{\mathrm{e}}$ the equilibrium concentration
( $\mathrm{mg} \mathrm{L}^{-1}$ ), and $\mathrm{m}$ the adsorbent mass (g). All experiments were performed in triplicate.

\section{Results and Discussion}

The powder XRD pattern of the synthesized Al-MCM-41 sample, shown in Figure 1a, presents four peaks in the low angle region from 1 to $8^{\circ}$, which were indexed as (100), (110), (200) and (210), and are consistent with a hexagonal lattice symmetry, typical of mesoporous Al-MCM-41 structure. ${ }^{30}$ The interplanar distance of the [100] direction $\left(\mathrm{d}_{100}\right)$ is $3.48 \mathrm{~nm}$ and the hexagonal unit cell parameter $\left(\mathrm{a}_{\mathrm{o}}\right)$, which is equal to the internal pore diameter plus the pore wall thickness, ${ }^{31}$ was calculated by $\mathrm{a}_{\mathrm{o}}=2 \mathrm{~d}_{100} / \sqrt{3}$, giving $4.02 \mathrm{~nm}$. These results are consistent with the results reported in the literature and indicate a wellstructured mesoporous arrangement. ${ }^{32-34}$ In the high angle range of 5 to $50^{\circ}$, no diffraction peaks were observed for AlMCM-41, which indicates the absence of other aluminum compounds and confirms the amorphous nature of the material (see Supplementary Information). Figure $1 \mathrm{~b}$ shows the XRD pattern for the sample CTAB-Al-MCM-41, which corresponds to the as-synthesized Al-MCM-41 sample, i.e., the sample without calcination. Although the main peak is not well resolved, it is possible to identify an intense signal in the region corresponding to the (100) peak. After the calcination, as it can be observed, XRD peaks appear more intense and much better resolved, with $2 \theta$ positions tending to be dislocated to higher angles, indicating additional condensation of the framework, which results in a contraction of the lattice as the surfactant is extracted

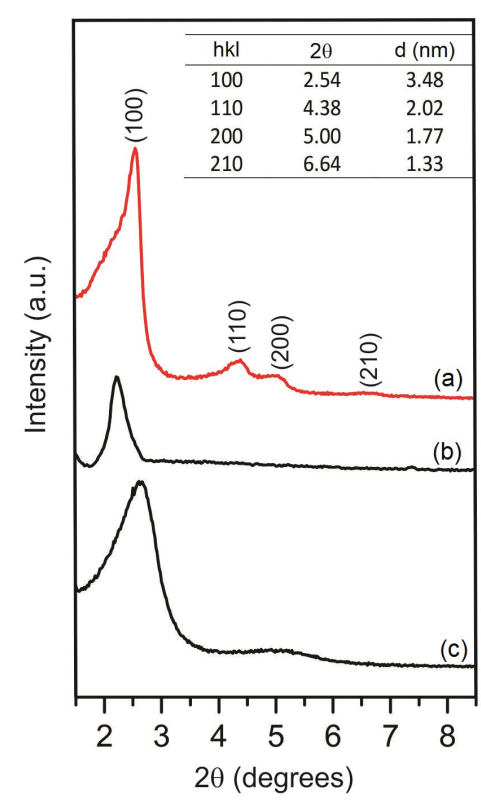

Figure 1. Powder XRD pattern of (a) Al-MCM-41, (b) CTAB-AlMCM-41 and (c) MCM-41. 
Table 1. Chemical composition measured by XRF

\begin{tabular}{lcccccc}
\hline Sample & $\mathrm{SiO}_{2} /$ wt. $\%$ & $\mathrm{Al}_{2} \mathrm{O}_{3} /$ wt. $\%$ & $\mathrm{~K}_{2} \mathrm{O} /$ wt. $\%$ & $\mathrm{Fe}_{2} \mathrm{O}_{3} /$ wt. $\%$ & Other $^{\mathrm{a}} / \mathrm{wt}^{2} \%$ & $\mathrm{Si} / \mathrm{Al}$ \\
\hline Kaolin & 61.719 & 33.559 & 1.852 & 2.664 & 0.206 & 1.6 \\
Metakaolin & 62.404 & 31.568 & 1.934 & 1.998 & 2.096 & 1.7 \\
Dealuminated metakaolin & 95.166 & 2.516 & 1.359 & 0.332 & 0.627 & 31.6 \\
Al-MCM-41 & 95.354 & 2.558 & 1.198 & 0.332 & 0.558 & 32.1 \\
\hline
\end{tabular}

${ }^{\mathrm{a}} \mathrm{Na}_{2} \mathrm{O}, \mathrm{SrO}, \mathrm{P}_{2} \mathrm{O}_{5}, \mathrm{Ag}_{2} \mathrm{O}$ and $\mathrm{Y}_{2} \mathrm{O}_{3}$. Al-MCM-41: Al-Mobil Composition of Matter No. 41 mesoporous material.

and in the porous structure improvement. The XRD pattern of the sample MCM-41 is presented in Figure 1c. The peak (100) appears at $2.59^{\circ}$, but with poorer resolution when compared to the sample containing aluminum.

The chemical compositions of the samples are shown in Table 1. The thermal activation of kaolin, i.e., its conversion to metakaolin by calcination, affects only slightly the aluminum concentration, maintaining the $\mathrm{Si} / \mathrm{Al}$ essentially unaltered, and is an important step for increasing the reactivity of the clay. ${ }^{35}$ The dealumination process implies in the Si/Al ratio increasing from 1.7 to 31.6, indicating the removal of a significant amount of aluminum, creating a more suitable condition for the mesoporous materials synthesis since a low $\mathrm{Si} / \mathrm{Al}$ value induces the formation of aluminum-rich dense phase. ${ }^{36}$ The final Si/Al ratio observed for the Al-MCM-41 sample is 32.1 , which is essentially the same as the dealuminated metakaolin precursor.

The infrared vibrational spectra of kaolin, metakaolin, dealuminated metakaolin and Al-MCM-41 are shown in Figure 2.

In Figure 2a, the bands that appear in the region between 1032 and $430 \mathrm{~cm}^{-1}$ are typical of kaolin. ${ }^{37}$ The lack of these

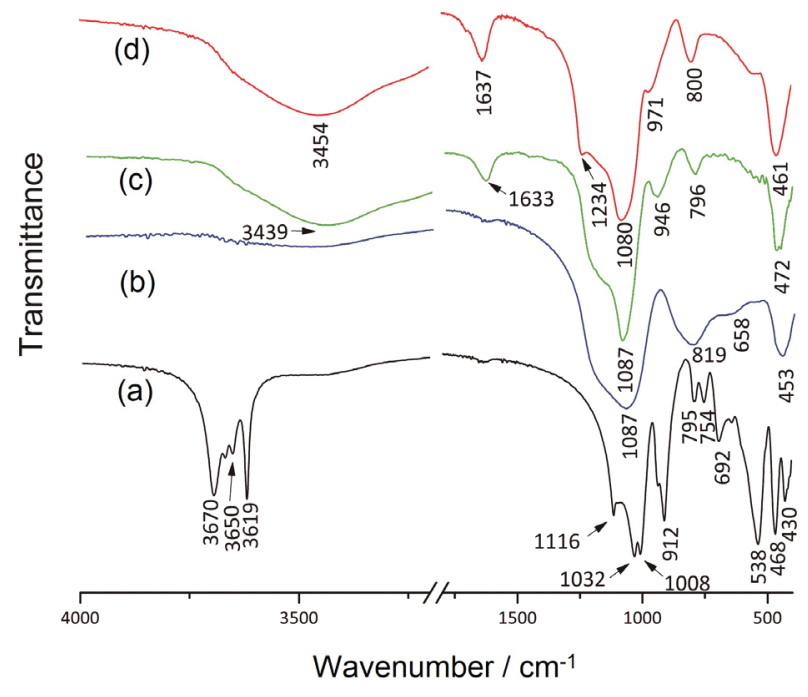

Figure 2. FTIR spectra of (a) kaolin, (b) metakaolin, (c) dealuminated metakaolin and (d) Al-MCM-41. bands in Figure 2b indicates loss of the crystalline structure of the clay after the calcination step, giving rise to its amorphous form metakaolin. The bands at 3695 and $3619 \mathrm{~cm}^{-1}$ that appear in the kaolin spectrum were not observed in the metakaolin spectrum, which means loss of water from kaolin, since these bands are related to the presence of $\mathrm{OH}$ groups. ${ }^{21}$ According to Du and Yang, ${ }^{38}$ calcination leads to the break of the kaolin crystalline structure, which can be verified by means of the metakaolin spectrum (Figure 2b), in which a broad band results from the superposition of the bands at 1116 and $1008 \mathrm{~cm}^{-1}$ observed in kaolin spectrum (Figure 2a), as well as the superposition of the bands between 793 and $754 \mathrm{~cm}^{-1}$ result in another broad band. Dealuminated metakaolin has its spectrum shown in Figure 2c. A broad band at $3439 \mathrm{~cm}^{-1}$ can be attributed to the surface containing silanol groups together with adsorbed water molecules. ${ }^{24}$ The bands at 946 and $796 \mathrm{~cm}^{-1}$, related to stretching of silanol groups and tetrahedrally-coordinated silicon, appear after the acid treatment and indicate an efficient process towards the aluminum removal. Figure $2 d$ shows the FTIR spectrum for Al-MCM-41. The bands observed at 3454 and $1637 \mathrm{~cm}^{-1}$ correspond to water adsorption by silanol groups located on the surface of the mesoporous material and the vibrational deformation of adsorbed water, respectively. ${ }^{21,39}$ The band at $1234 \mathrm{~cm}^{-1}$ is typical of silica/aluminosilicate mesoporous materials. ${ }^{40}$

The $\mathrm{N}_{2}$ adsorption-desorption isotherms for the calcined Al-MCM-41, together with its pore size distribution calculated by using the BJH method, are shown in Figure 3.

The shape of the isotherm is consistent with a type IV by the International Union of Pure and Applied Chemistry (IUPAC) classification, ${ }^{41}$ and the observed hysteresis loop is characteristic of a mesoporous material, with tubular mesopores in an ordered hexagonal array. ${ }^{42}$ The BET surface specific area was $1,303 \mathrm{~m}^{2} \mathrm{~g}^{-1}$, with a pore volume of $1.19 \mathrm{~cm}^{3} \mathrm{~g}^{-1}$, values considered high for this kind of material. ${ }^{24,43,44}$ The sharp inflection at about $\mathrm{P} / \mathrm{P}_{\mathrm{o}}=0.26$, also called point $\mathrm{B}$, indicates the stage from monolayer coverage to multilayer adsorption, and corresponds to capillary condensation within uniform mesopores and a narrow pore size distribution of uniform size. ${ }^{38,45} \mathrm{~A}$ plateau 

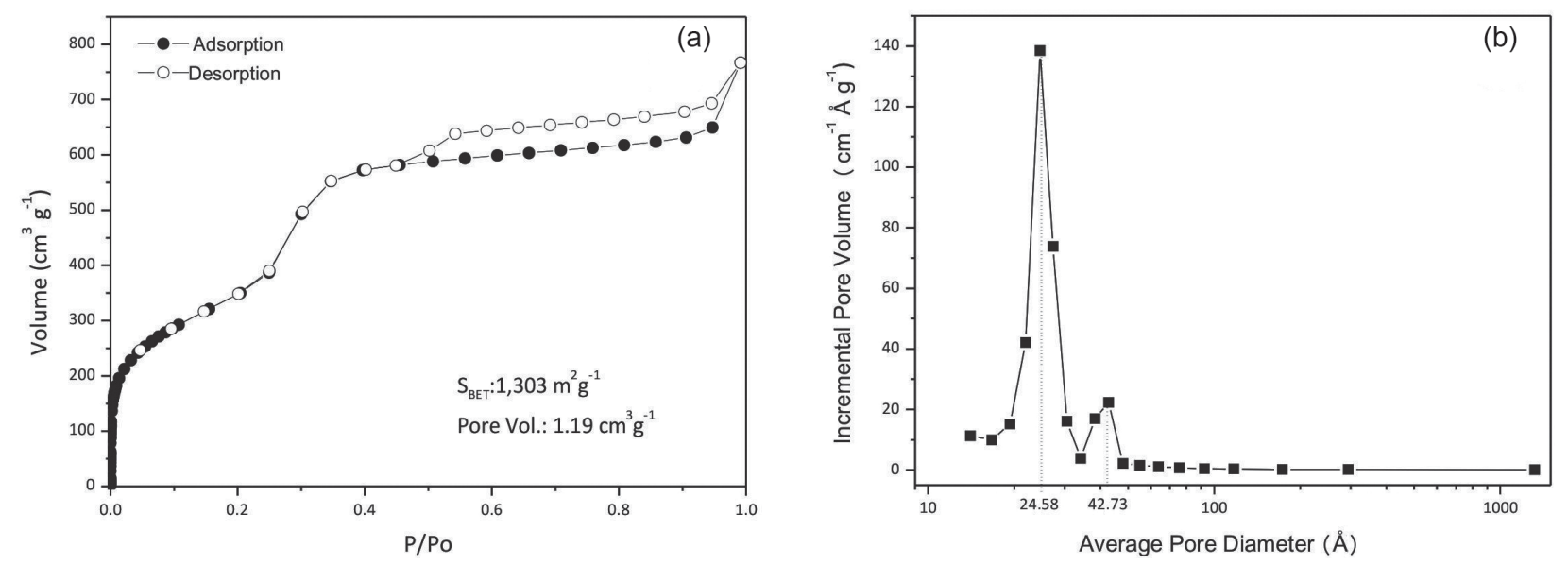

Figure 3. (a) Nitrogen adsorption-desorption isotherms for the calcined Al-MCM-41 and (b) its pore size distribution.

with a slight inclination at high values of relative pressures is also observed, and may be associated with multilayer adsorption on the external surface. ${ }^{46}$ An uptake at relative pressure close to 1.0 indicates the existence of macropores, probably resulting from agglomeration of small particles. ${ }^{47}$ The pore size distribution (Figure $3 b$ ) presents a main sharp peak centered at $2.4 \mathrm{~nm}$, showing the presence of uniform mesopores.

Figure 4 shows the thermogravimetric curves, and the corresponding derivative curves of CTAB, as-synthesized Al-MCM-41 and Al-MCM-41. These analyses were carried out targeting information about the thermal stability of the Al-MCM-41 as well as the removal of CTAB. The principal data are summarized in Table 2.

In order to simplify the presentation of data, the thermogravimetric events were named as A, B and C for which each set of percentage of weight loss and correspondent temperature range is presented. All weight of CTAB is lost when the temperature reaches $218^{\circ} \mathrm{C}$. The as-synthesized sample Al-MCM-41(CTAB-Al-MCM-41) presents three events. The first one (event A) that takes place below $100{ }^{\circ} \mathrm{C}$ is related to water loss. The second event (B) takes place between 123 and $227{ }^{\circ} \mathrm{C}$, in which $21.7 \%$ of weight loss is verified. This loss corresponds to the elimination of the surfactant CTAB within the material structure, which is in accordance with what is observed in the thermogravimetric curve of CTAB sample. The event $\mathrm{C}$ occurs between 251 and $268{ }^{\circ} \mathrm{C}$ and shows a weight loss of about $2 \%$, which can be associated with elimination of surfactant residues. The thermogravimetric curves for the sample Al-MCM-41 show a residual weight of about $80 \%$. Most of the lost weight should correspond to absorbed water, but it is possible that weight loss in higher temperatures is associated with decomposition of silanol groups.

The ${ }^{29} \mathrm{Si}$ and ${ }^{27} \mathrm{Al}$ NMR spectra for Al-MCM-41 and the raw material used in its synthesis, i.e., kaolin, as well as the intermediates are presented in Figure 5. The ${ }^{29} \mathrm{Si} \mathrm{NMR}$ signals are referred to as $\mathrm{Qn}=\mathrm{Si}[\mathrm{nSi},(4-\mathrm{n}) \mathrm{OH}]$, or $\mathrm{Si}$ [nSi, $(4-\mathrm{n}) \mathrm{Al}]$, in which $\mathrm{n}$ varies from 1 to $4{ }^{48}$ In Figure 5a, a single narrow signal at $-92 \mathrm{ppm}\left(\mathrm{Q}_{2}\right)$ in the ${ }^{29} \mathrm{Si} \mathrm{NMR}$ spectrum is characteristic of four-coordinate tetrahedral silicon, which is bonded to other four silicon atoms through oxygen. ${ }^{49}$ When kaolin is thermally activated, giving rise to metakaolin, a broad peak is observed (Figure 5b) indicating a series of different chemical and structural environments around the silicon atom, which results from the dehydroxylation followed by changes in $\mathrm{Si}-\mathrm{O}-\mathrm{Si}(\mathrm{Al})$ bond angles. This scenario is usually found in amorphous silicates. ${ }^{50}$ The ${ }^{29} \mathrm{Si}$ NMR spectrum for acid treated sample is shown in Figure 5c, with two main signals at -102 and $-109 \mathrm{ppm}$. The first signal is typical of the appearance of free silanol groups, $(\mathrm{SiO})_{3} \mathrm{SiOH}$, indicated as silicon site $\mathrm{Q}_{3}$, as the species $(\mathrm{SiO})_{3} \mathrm{SiOAl}$ undergo a partial replacement of the aluminum by hydrogen atoms. When the silanol structures condense, they generate the siloxane groups, $(\mathrm{SiO})_{4} \mathrm{Si}$, which are evidenced by the signal at $-109 \mathrm{ppm}$, described as $\mathrm{Q}_{4}$ sites. ${ }^{38}$ This is a strong indication that not only has the original two-dimensional stable structure existing in kaolin been lost, but also that the three-dimensional expected structure for the Al-MCM-41 begins to be observable. The ${ }^{29} \mathrm{Si} \mathrm{NMR}$ spectrum in Figure 5d, for the synthesized Al-MCM-41, shows three signals, indicated as $\mathrm{Q}_{2}, \mathrm{Q}_{3}$ and $\mathrm{Q}_{4}$. There is a clear predominance of $\mathrm{Q}_{4}$ sites over the others, since the signal at $-109 \mathrm{ppm}$ presents higher intensity, which indicates highly cross-linked framework walls. ${ }^{51}$ Furthermore, the $\mathrm{Q}_{3} / \mathrm{Q}_{4}$ ratio provides a way of measuring the degree of silanol group condensation: the smaller this ratio the higher the degree of silanol condensation..$^{48}$

In Figure 5a, a single strong peak at $\delta=-2.5 \mathrm{ppm}$ is observed in the ${ }^{27} \mathrm{Al} \mathrm{NMR}$, which might be assigned to 6-coordinated $\mathrm{Al}\left(\mathrm{Al}^{\mathrm{VI}}\right) .{ }^{52} \mathrm{After}$ being converted to metakaolin by thermal activation at $773 \mathrm{~K}$, three peaks are observed in 
the ${ }^{27} \mathrm{Al}$ NMR spectrum (Figure $5 \mathrm{~b}$ ). While the signal at 3 ppm indicates that most of the aluminum in the metakaolin
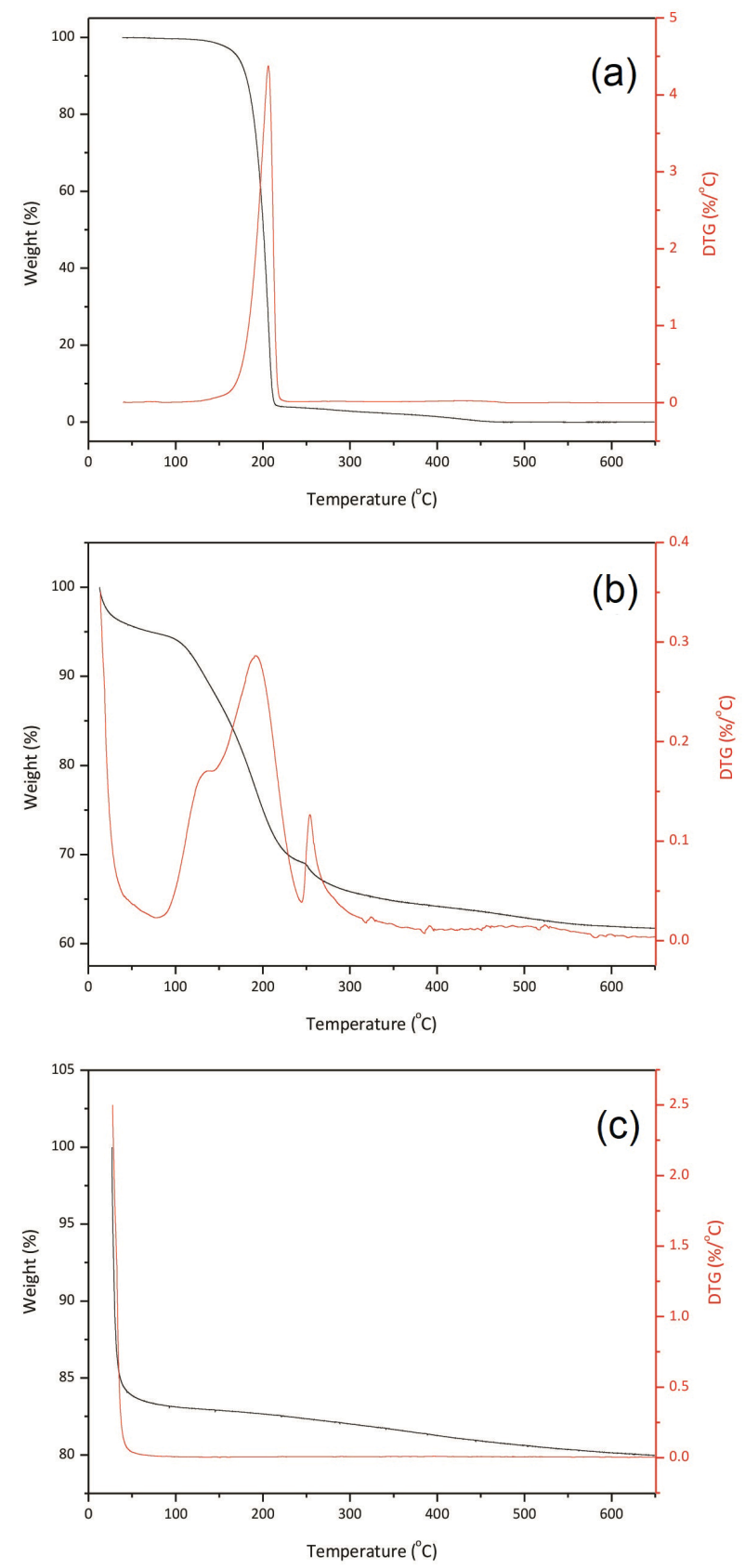

Figure 4. TG and derivative TG (DTG) for (a) CTAB, (b) as-synthesized Al-MCM-41 and (c) Al-MCM-41. maintains itself in the original kaolin form, the signal at $55 \mathrm{ppm}$ shows the formation of tetrahedrally coordinated Al, which results from the partial destruction of the octahedrally arranged aluminum in the kaolin structure, which can be represented by the equation: $\left[\mathrm{AlO}_{2}(\mathrm{OH})_{4}\right] \rightarrow \mathrm{AlO}_{4}+2 \mathrm{H}_{2} \mathrm{O} .^{24}$ The third signal, at $24 \mathrm{ppm}$, is attributed to the presence of 5-coordinated $\mathrm{Al}^{\mathrm{v}},{ }^{49}$ an intermediate whose signal disappears when the acid treatment is carried out, as can be seen in Figure $5 \mathrm{c}$. If a complete conversion of kaolin into the amorphous Al-MCM-41 took place, the three aluminum species present in the metakaolin should be completely converted to tetrahedral $\mathrm{Al}^{\mathrm{IV}}$, generating a single signal for tetrahedrally coordinated $\mathrm{Al}, \mathrm{Al}^{\mathrm{IV}}$ in the framework of material. ${ }^{51}$ However, the ${ }^{27} \mathrm{Al}$ NMR spectrum exhibits two main signals, at 55 and 3 ppm (Figure 5d), attributed to tetrahedrally coordinated framework aluminum and octahedrally coordinated non-framework aluminum, the latter probably in the form of $\left[\mathrm{Al}\left(\mathrm{H}_{2} \mathrm{O}_{6}\right)\right]^{3+}$ inside the pores. ${ }^{38,48}$

Kaolin can present either low, medium or high crystalline order depending on its genesis, and the kind of crystal order affects considerably its reactivity. ${ }^{53}$ SEM micrograph of kaolin provides a quick way to evaluate such property. From Figure 6a, one may clearly note the existence of flat plate particles with sizes of around $1 \mu \mathrm{m}$. Figure $6 \mathrm{~b}$ shows the flat particles stacked together. When kaolin is thermally treated, it is converted to its metakaolin form, which is shown in Figures 6c and 6d. In this case, no appreciable changes can be observed by means of microscopy. After the acid treatment of the metakaolin (Figures 6e and 6f), although the flat particles are still observable, a decrease in their thickness can be inferred due to the acid attack. It is important to notice that such attack is directed for the aluminum removal. From Figures $6 \mathrm{~g}$ and $6 \mathrm{~h}$, it can be seen that the characteristic form of kaolin, and its direct derivatives, tends to change giving rise to particles with non-uniform shapes.

Figure 7 shows the images of the Al-MCM-41 samples obtained from TEM. Figure 7a shows a cross-sectional view along the [100] direction, in which it is easily noticed that the mesoporous material contains regular arrangements of hexagonal pores in a honeycomb arrangement. In

Table 2. Thermogravimetric summary for samples CTAB, CTAB-Al-MCM-41 and Al-MCM-41

\begin{tabular}{|c|c|c|c|c|c|c|c|}
\hline \multirow{2}{*}{ Sample } & \multicolumn{3}{|c|}{ Temperature $/{ }^{\circ} \mathrm{C}$} & \multicolumn{3}{|c|}{ Percentage / \% } & \multirow{2}{*}{ Residue / \% } \\
\hline & Event A & Event B & Event $\mathrm{C}$ & Event A & Event B & Event $\mathrm{C}$ & \\
\hline СТАВ & - & $158-218$ & - & - & 96.0 & - & 0.0 \\
\hline CTAB-Al-MCM-41 & $22-83$ & $123-227$ & $251-268$ & 5.3 & 21.7 & 2.0 & 61.7 \\
\hline Al-MCM-41 & $27-51$ & - & - & 16.2 & - & - & 79.9 \\
\hline
\end{tabular}

CTAB: cetyltrimethylammonium bromide; Al-MCM-41: Al-Mobil Composition of Matter No. 41 mesoporous material. 


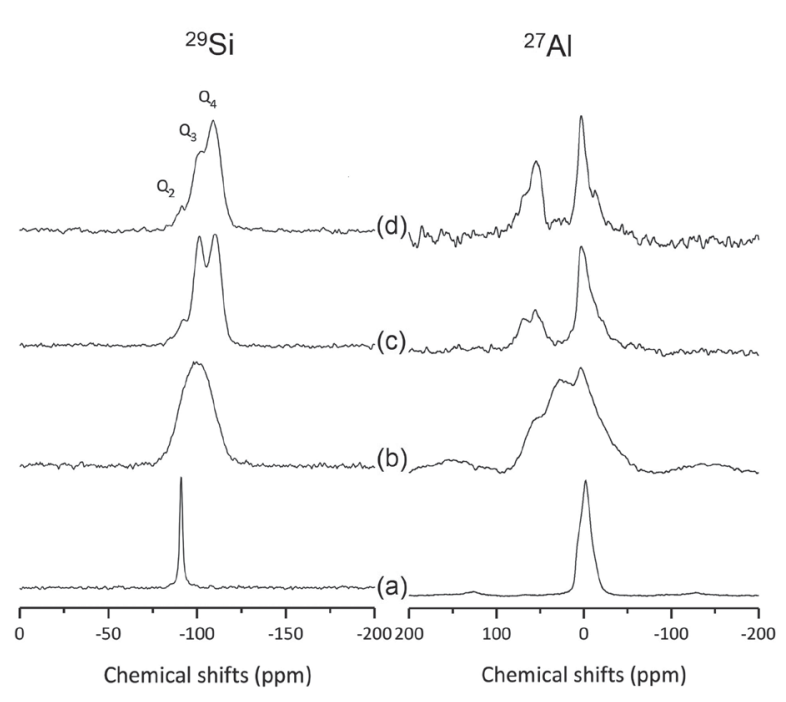

Figure 5. ${ }^{29} \mathrm{Si}$ (left) and ${ }^{27} \mathrm{Al}$ (right) solid-state NMR spectra of (a) kaolin, (b) metakaolin, (c) dealuminated metakaolin and (d) Al-MCM-41.
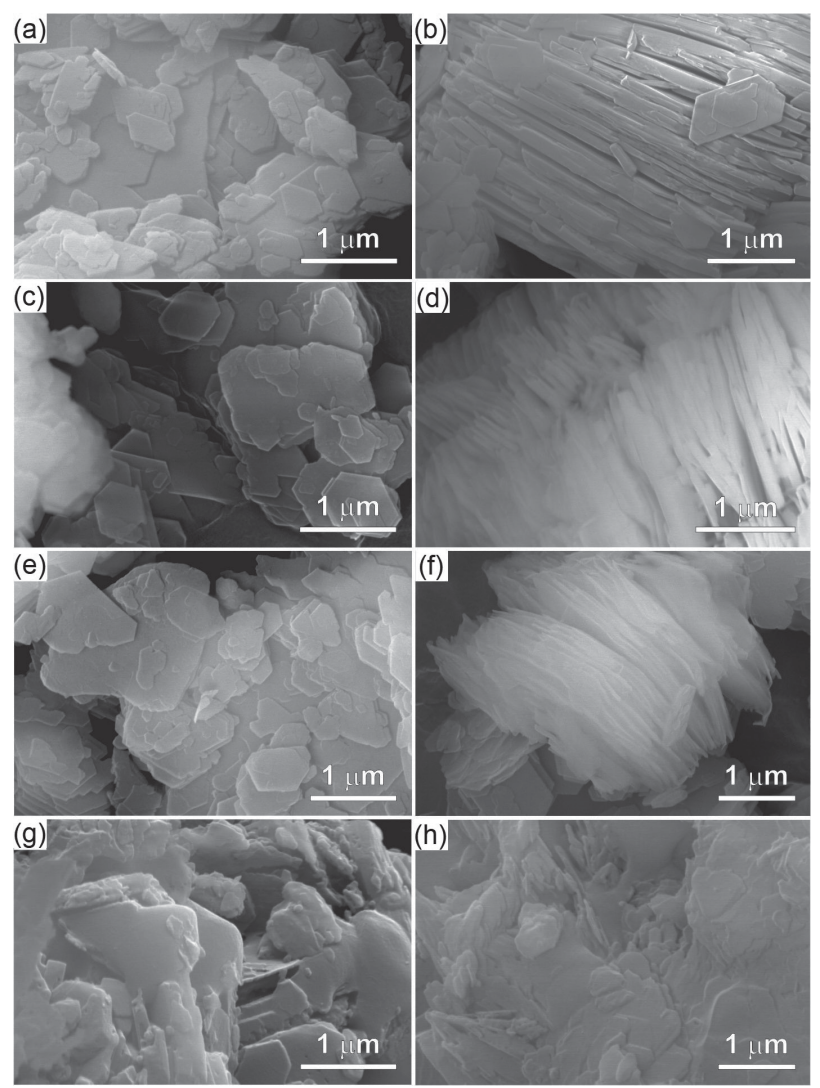

Figure 6. SEM micrographs of (a and b) kaolin, (c and d) metakaolin, (e and f) dealuminated metakaolin and ( $g$ and h) Al-MCM-41.

Figure 7b, well-ordered arrays of hexagonal channels are also observable. The average size of the mesopores agrees with what is observed in nitrogen adsorption-desorption isotherms. These micrographs reinforce that the material possesses a uniform pore system, as inferred from the X-ray patterns as well.
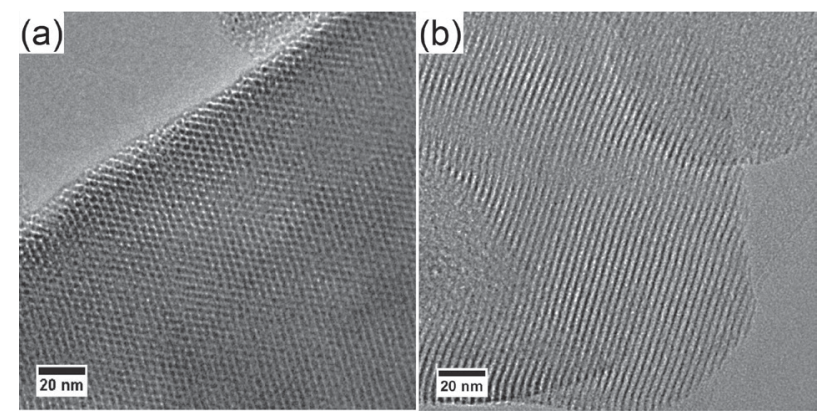

Figure 7. TEM images of Al-MCM-41 along the (a) [100] direction and (b) [110] direction.

The contact time of MB on Al-MCM-41 is shown in Figure $8 \mathrm{a}$. A simple analysis indicates that for the conditions used, the maximum MB removal (about 99\%) is verified in the first $5 \mathrm{~min}$. The isotherm data on the adsorption of MB on Al-MCM-41 are presented in Figure 8b. The adsorption isotherm shows the distribution of the adsorption molecules between the liquid phase and the solid phase when the adsorption process reaches equilibrium. ${ }^{54}$ The observed adsorption increases with the increment of $\mathrm{MB}$ concentrations, as expected, until the equilibrium is reached.

The adsorption data for MB on the sample Al-MCM-41 were analyzed by Langmuir model, which assumes that the adsorption occurs on a homogenous surface with no interaction between adsorbates in the plane of the surface. ${ }^{55,56}$ The isotherm can be represented as follows:

$\mathrm{q}_{\mathrm{e}}=\frac{\mathrm{q}_{\max } \mathrm{K}_{\mathrm{L}} \mathrm{C}_{\mathrm{e}}}{1+\mathrm{K}_{\mathrm{L}} \mathrm{C}_{\mathrm{e}}}$

where $\mathrm{q}_{\max }$ is the theoretical maximum adsorption capacity $\left(\mathrm{mg} \mathrm{g}^{-1}\right.$ ) and $\mathrm{K}_{\mathrm{L}}$ is the Langmuir constant. Langmuir shape of the isotherm means that there is no strong competition between the solvent and the adsorbate to occupy the adsorbent sites, indicating the high potential of Al-MCM-41 as adsorbent for MB ${ }^{57}$ The maximum adsorption capacity was determined according to the linear form of the Langmuir isotherm:

$\frac{\mathrm{C}_{\mathrm{e}}}{\mathrm{q}_{\mathrm{e}}}=\frac{1}{\mathrm{q}_{\max }} \mathrm{C}_{\mathrm{e}}+\frac{1}{\mathrm{q}_{\max } \mathrm{K}_{\mathrm{L}}}$

The theoretical maximum adsorption capacity of the synthesized Al-MCM-41 for MB, as obtained from Figure 8c, was $316 \mathrm{mg} \mathrm{g}^{-1}$, and the Langmuir constant $9.42 \times 10^{-3} \mathrm{~L} \mathrm{mg}^{-1}$. These values are higher than those reported for other mesoporous materials such as modified clays $\left(62 \mathrm{mg} \mathrm{g}^{-1}\right),{ }^{58}$ and carbons $\left(262 \mathrm{mg} \mathrm{g}^{-1}\right),{ }^{59}$ and is comparable to activated carbon (333 $\left.\mathrm{mg} \mathrm{g}^{-1}\right),{ }^{7}$ the latter with the disadvantage of being difficult 

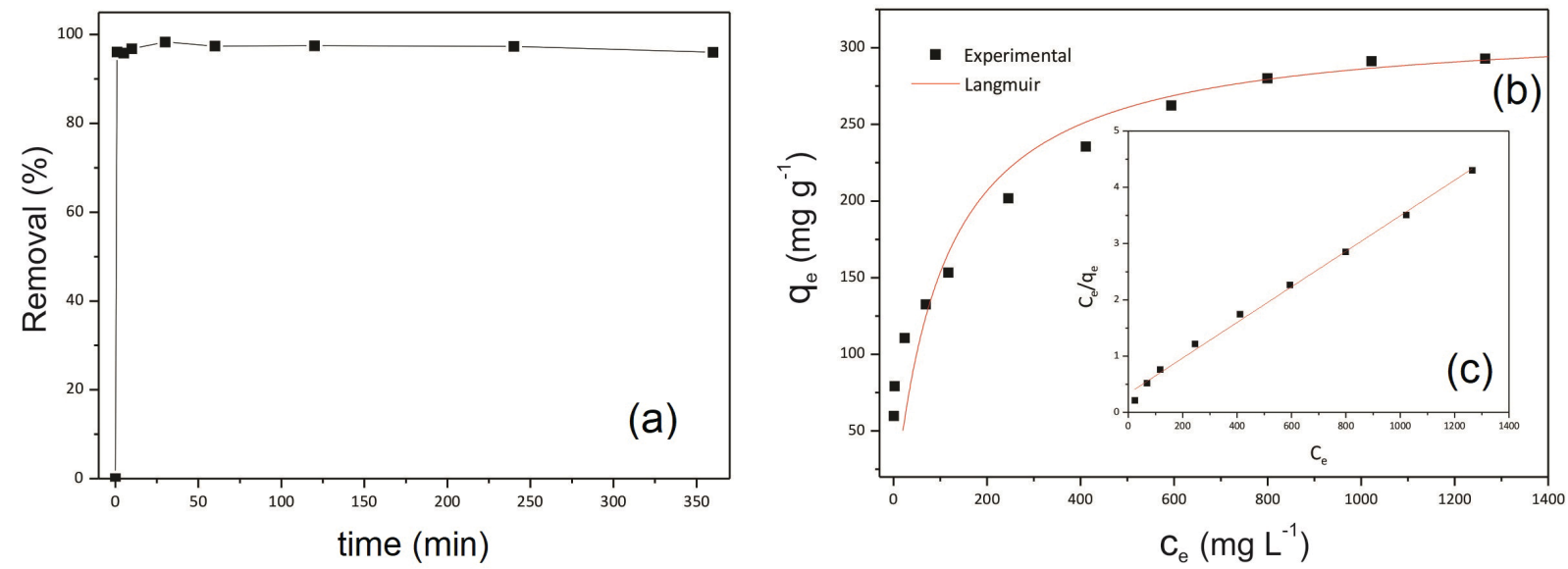

Figure 8. (a) Contact time of MB adsorbed on Al-MCM-41, (b) adsorption isotherm and (c) Langmuir plot.

to be reused. A hydroxylated surface of the Al-MCM-41, due to silanol groups, is probably the main responsible for the strong interactions between the MB molecules and the material mesopores.

\section{Conclusions}

Synthesis of the mesoporous material Al-MCM-41 by hydrothermal route using kaolin as the main raw material was successfully achieved. The dealumination process led to an increase of the $\mathrm{Si} / \mathrm{Al}$ ratio so that the reaction mixture could be suitable for the synthesis of Al-MCM-41. The identification of Al-MCM-41 was indicated by the results of characterization techniques such XRD, electronic microscopy, $\mathrm{N}_{2}$ adsorption/desorption, FTIR, thermal analysis and ${ }^{29} \mathrm{Si}$ and ${ }^{27} \mathrm{Al} \mathrm{NMR}$. Properties such as the high surface area $\left(1,303 \mathrm{~m}^{2} \mathrm{~g}^{-1}\right)$ and the relatively high thermal stability indicate that the obtained material can be useful in a variety of applications, with the advantage of being made by means of a cost-effective process, with the kaolin employed as raw material. The adsorption experiments reveal that the Al-MCM-41 synthesized is an effective adsorbent for MB removal in aqueous solution, with a theoretical maximum adsorption capacity of $316 \mathrm{mg} \mathrm{g}^{-1}$, reaching equilibrium in few minutes. These results indicate that the Al-MCM-41 obtained from kaolin could be considered as a potential adsorbent for MB removal from aqueous media.

\section{Supplementary Information}

Supplementary information is available free of charge at http://jbcs.sbq.org.br as PDF file.

\section{Acknowledgments}

The authors acknowledge Laboratório Nacional de
Nanotecnologia (LNNano/CNPEM) for providing the equipment and technical support for the experiments involving TEM; Central Analítica of Universidade Federal do Ceará (UFC/CT-INFRA/MCTI-SISNANO/ Pró-equipamentos-CAPES) for technical support and experiments of SEM; Prof H. O. Pastore for helping with low angle XRD analyses; and the Brazilian Ministry of Education-CAPES, CNPq and FUNCAP for financial support.

\section{References}

1. Gibson, L. T.; Chem. Soc. Rev. 2014, 43, 5173.

2. Jamal, F.; Qidwai, T.; Pandey, P. K.; Singh, D.; Catal. Commun. 2011, 15, 93.

3. Eftekhari, S.; Habibi-Yangjeh, A.; Sohrabnezhad, S.; J. Hazard. Mater. 2010, 178, 349.

4. Torres, E.; Bustos-Jaimes, I.; Le Borgne, S.; Appl. Catal., B 2003, 46, 1 .

5. Zhang, P.; Lo, I.; O’Connor, D.; Pehkonen, S.; Cheng, H.; Hou, D.; J. Colloid Interface Sci. 2017, 508, 39.

6. Rafatullah, M.; Sulaiman, O.; Hashim, R.; Ahmad, A.; J. Hazard. Mater. 2010, 177, 70.

7. Ma, J.; Huang, D.; Zou, J.; Li, L.; Kong, Y.; Komarneni, S.; J. Porous Mater. 2015, 22, 301.

8. Lee, C. K.; Liu, S. S.; Juang, L. C.; Wang, C. C.; Lin, K. S.; Lyu, M. D.; J. Hazard. Mater. 2007, 147, 997.

9. Karim, A. H.; Jalil, A. A.; Triwahyono, S.; Sidik, S. M.; Kamarudin, N. H. N.; Jusoh, R.; Jusoh, N. W. C.; Hameed, B. H.; J. Colloid Interface Sci. 2012, 386, 307.

10. Wu, Z.; Lu, Q.; Fu, W. H.; Wang, S.; Liu, C.; Xu, N.; Wang, D.; Wang, Y. M.; Chen, Z.; New J. Chem. 2015, 39, 985 .

11. Sterczynska, A.; Derylo-Marczewska, A.; Zienkiewicz-Strzalka, M.; Sliwinska-Bartkowiak, M.; Domin, K.; Langmuir 2017, 33, 11203. 
12. Bhattacharyya, S.; Lelong, G.; Saboungi, M. L.; J. Exp. Nanosci. 2006, 1, 375 .

13. Alothman, Z. A.; Materials 2012, 5, 2874.

14. Abu-Zied, B. M.; Schwieger, W.; Asiri, A. M.; Microporous Mesoporous Mater. 2015, 218, 153.

15. Kang, F.; Wang, Q.; Xiang, S.; Mater. Lett. 2005, 59, 1426.

16. Liu, T.; Jin, F.; Wang, X.; Fan, Y.; Yuan, M.; Catal. Today 2017, 297, 316.

17. Li, C.-C.; Qiao, X.-C.; Yu, J.-G.; Mater. Lett. 2016, 167, 246.

18. Adjdir, M.; Bendeddouche, C. K.; Benhaoua, H.; Kaid, M.; Karmaoui, M.; Boudinar, M.; Weidler, P. G.; C. R. Chim. 2015, 18,375 .

19. Panek, R.; Wdowin, M.; Franus, W.; Czarna, D.; Stevens, L. A.; Deng, H.; Liu, J.; Sun, C.; Liu, H.; Snape, C. E.; J. CO2 Util. 2017, 22, 81 .

20. Kumar, P.; Mal, N.; Oumi, Y.; Yamana, K.; Sano, T.; J. Mater. Chem. 2001, 11, 3285.

21. Xie, Y.; Zhang, Y.; Ouyang, J.; Yang, H.; Phys. Chem. Miner. 2014, 41, 497.

22. Juang, L.-C.; Wang, C.-C.; Lee, C.-K.; Chemosphere 2006, 64, 1920.

23. La-Salvia, N.; Lovon-Quintana, J. J.; Lovon, A. S. P.; Valenca, G. P.; Mater. Res. 2017, 20, 1461.

24. Wang, G.; Wang, Y.; Liu, Y.; Liu, Z.; Guo, Y.; Liu, G.; Yang, Z.; Xu, M.; Wang, L.; Appl. Clay Sci. 2009, 44, 185.

25. Luan, Z.; Cheng, C.-F.; Zhou, W.; Klinowski, J.; J. Phys. Chem. 1995, 99, 1018.

26. Corma, A.; Fornes, V.; Navarro, M. T.; Perezpariente, J.; J. Catal. 1994, 148, 569.

27. Kosslick, H.; Lischke, G.; Parlitz, B.; Storek, W.; Fricke, R.; Appl. Catal., A 1999, 184, 49.

28. Antonakou, E.; Lappas, A.; Nilsen, M. H.; Bouzga, A.; Stöcker, M.; Fuel 2006, 85, 2202.

29. Okada, K.; Yoshizaki, H.; Kameshima, Y.; Nakajima, A.; Appl. Clay Sci. 2008, 41, 10.

30. Adjdir, M.; Ali-Dahmane, T.; Friedrich, F.; Scherer, T.; Weidler, P. G.; Appl. Clay Sci. 2009, 46, 185.

31. Kraleva, E.; Saladino, M. L.; Spinella, A.; Nasillo, G.; Caponetti, E.; J. Mater. Sci. 2011, 46, 7114.

32. Fu, P.; Yang, T.; Feng, J.; Yang, H.; J. Ind. Eng. Chem. 2015, 29, 338.

33. Beck, J. S.; Vartuli, J. C.; Roth, W. J.; Leonowicz, M. E.; Kresge, C. T.; Schmitt, K. D.; Chu, C. T.-W.; Olson, D. H.; Sheppard, E. W.; McCullen, S. B.; Higgins, J. B.; Schlenkert, J. L.; J. Am. Chem. Soc. 1992, 114, 10834.

34. Brahmi, L.; Ali-Dahmane, T.; Hamacha, R.; Hacini, S.; J. Mol. Catal. A: Chem. 2016, 423, 31.

35. Loiola, A. R.; Andrade, J.; Sasaki, J. M.; da Silva, L. R. D.; J. Colloid Interface Sci. 2012, 367, 34.
36. Kloetstra, K. R.; Zandbergen, H. W.; van Bekkum, H.; Catal. Lett. 1995, 33, 157.

37. Besoain, N.; Mineralogia de Arcillas de Suellos, $5^{\text {th }}$ ed.; IICA: San José, 1985.

38. Du, C.; Yang, H.; J. Colloid Interface Sci. 2012, 369, 216.

39. Yang, X.-Y.; Tian, G.; Chen, L.-H.; Li, Y.; Rooke, J. C.; Wei, Y.-X.; Liu, Z.-M.; Deng, Z.; Van Tendeloo, G.; Su, B.-L.; Chem. - Eur. J. 2011, 17, 14987.

40. Yang, H.; Deng, Y.; Du, C.; Jin, S.; Appl. Clay Sci. 2010, 47, 351.

41. Sing, K. S. W.; Everett, D. H.; Haul, R. A. W.; Moscou, L.; Pierotti, R. A.; Rouquerol, J.; Siemieniewska, T.; Pure Appl. Chem. 1985, 57, 603.

42. Marianou, A. A.; Michailof, C. M.; Pineda, A.; Iliopoulou, E. F.; Triantafyllidis, K. S.; Lappas, A. A.; Appl. Catal., A 2018, 555,75 .

43. Kim, J.; Shim, B.; Lee, G.; Han, J.; Kim, J. M.; Jeon, J. K.; Catal. Today 2018, 303, 71.

44. Cho, Y.-H.; Kim, C. H.; Lee, S. H.; Han, J.; Kwon, T. S.; Lee, K.-Y.; Fuel 2018, 221, 399.

45. Jin, S.; Qiu, G.; Xiao, F.; Chang, Y.; Wan, C.; Yang, M.; J. Am. Ceram. Soc. 2007, 90, 957.

46. Hui, K. S.; Chao, C. Y. H.; J. Hazard. Mater. 2006, 137, 1135.

47. Du, E.; Yu, S.; Zuo, L.; Zhang, J.; Huang, X.; Wang, Y.; Appl. Clay Sci. 2011, 51, 94.

48. Song, W.; Liu, X.; Jing, T.; Deng, Q.; Chin. J. Chem. Eng. 2012, $20,900$.

49. Akolekar, D.; Chaffee, A.; Howe, R. F.; Zeolites 1997, 19, 359.

50. Chandrasekhar, S.; Pramada, P. N.; Microporous Mesoporous Mater. 2008, 108, 152.

51. Hussain, M.; Song, S.-K.; Ihm, S.-K.; Fuel 2013, 106, 787.

52. Carrillo, A. I.; Serrano, E.; Serrano-Ruiz, J. C.; Luque, R.; Garcia-Martinez, J.; Appl. Catal., A 2012, 435-436, 1.

53. Lombardi, K. C.; Guimarães, J. L.; Mangrich, A. S.; Mattoso, N.; Abbate, M.; Schreiner, W. H.; Wypych, F.; J. Braz. Chem. Soc. 2002, 13, 270.

54. Hameed, B. H.; Ahmad, A. A.; J. Hazard. Mater. 2009, 164, 870.

55. Liu, T.; Li, Y.; Du, Q.; Sun, J.; Jiao, Y.; Yang, G.; Wang, Z.; Xia, Y.; Zhang, W.; Wang, K.; Zhu, H.; Wu, D.; Colloids Surf., B 2012, 90, 197.

56. Langmuir, I.; J. Am. Chem. Soc. 1918, 40, 1361.

57. Hamdaoui, O.; J. Hazard. Mater. 2006, 135, 264.

58. Auta, M.; Hameed, B. H.; Chem. Eng. J. 2012, 198-199, 219.

59. Yan, C.; Wang, C.; Yao, J.; Zhang, L.; Liu, X.; Colloids Surf., A 2009, 333, 115.

Submitted: February 19, 2018

Published online: June 18, 2018 